\title{
ANTITHYROID SUBSTANCE AND LEPROSY
}

\author{
by Dr. BERnARDO RoJAs, \\ Cali, Colombia, South America.
}

The theory behind the use of antithyroid substances in the treatment of leprosy was originally presented in 1957 by Dr. ARTURO O'BYRNE in a preliminary note to a meeting of directors of dispensaries and leprosaria of the Republic of Colombia. Later, in May 1958 Dr. O'BYRNE presented his thesis before the First National Congress of Leprology in the city of Cartagena, Colombia.

The importance of this theme is undoubted. I believe that the theory of the importance of iodine in relation to the bacteria will be of great assistance in solving the problem of rational therapeutics of leprosy.

One of the basic postulates which have to be investigated fully is that of seeking and finding existing analogies between known antithyroid drugs and leprostatic drugs; for the chemical, biochemical, and physiological relationships of the compounds in question show us that the basis of their action can be expressed as hypoiodaemic action affecting the thyroid gland directly, and indirectly the tissue iodine.

As a confirmed fact we know that the iodine of iodine compounds is very harmful to the leprosy patient. As A. O'BYRNE says "The relatively simple consequence that a substance administered in the course of an infectious disease is harmful to the patient and causes the multiplication of the infecting agent, derives from the fact that it enhances the vitality of the microbe at the expense of the life of the patient."

In future investigations we should take into account whether we should think of the leprosy patient more as an hyperiodaemic than as a hyperthyroid.

If the increase of iodine in the blood causes exacerbation of the lepromatous lesions, diminution of iodine in the blood can provoke a regression of the disease.

Up to this day leprosy lacks a specific and rapidly acting curative medicament, and this has not been due to lack of experimentation but to lack of exact knowledge about the pathogenesis, that is to say, we lack a 'biological model', for reasons known to all. Because we do not have this biological model in animal experimentation, the difficult therapeutic problem in leprosy must be studied directly in patients. So it is that in leprosy a logical lack of confidence exists in every new treatment which tries to rise.

Antithyroid drugs present as possibilities in the treatment of leprosy because of existing analogies between iodine on one hand, and the thyroid gland on the other, also between tissue iodine and the harmfulness of iodine, as much for tuberculosis as leprosy patients. 
The antithyroid substances are the most powerful antioxidants which can operate in the tissues; they operate through the medium of iodine and can change the background and make it favourable to the proliferation of the bacilli.

The thyroid gland has an enormous capacity to store iodine, up to 500 times more than any other body tissue.

In thyroid hyperactivity there is a diminution of thyroid iodine and an increase of blood iodine, both of which are signs of oversecretion of thyroxine. One can suppose an increase of tissue iodine.

The activity of the gland shows many variations. For example it decreases during old age, under raised temperatures, during chronic diseases, and as a result of toxic influences, etc. It increases through seasonal fluctuations, during adolescence, during childbirth, through emotional trauma, during the menopause, etc.

The leprosy patient undergoes frequent reactions in his disease, and these reactivations coincide, and not by mere chance with periods of thyroid hyperactivity. We have observed these outbreaks and leprosy reactions during the premenstrual epoch, during childbirth, in adolescence, in seasonal changes and even very often during emotional upsets, and we have seen their attenuation and the development of benign forms of leprosy in old age, when they are accompanied by other chronic diseases, or when there is a change caused by toxic influences.

One wonders if the leprosy patient could arrive at the stage of being considered as an atypical form of hyperiodaemic hyperthyroidism?

Various atypical forms of hyperthyroidism coincide with the initial typical forms suffered by most leprosy patients, namely the dyschromic forms (whether hyperchromic, acromic, or hypochromic); profuse sweating; amyotrophy and swellings of the limbs; neuritis and polyneuritis; muscular asthenia and functional impotence; impaired nutrition; hepatic insufficiency; hepatic lesions; psychophysical instability; changes in the mucosae, such as rhinitis; etc.

If we admit that the leprosy patient is a hyperiodaemic hyperthyroid, it can be expected that as a consequence of antithyroid treatment the stability of the thyroid gland is only attained after several months and even years, but this does not include the fact that the iodine concentration in the tissues and in the circulation may fall in a relatively short period of time.

The antithyroid substances work rapidly and surprisingly. alter 6 to 8 months the therapeutic progress is relatively slow. Inıs may be explained because the antithyroid drugs at present in use work more on the thyroid gland than on the tissue iodine, that is to say they impede the transport of glandular iodine to the ussues. 
The rapid initial improvement is explained by the decrease of the iodine in the blood and in the tissues.

Rosaline PitT-Rivers says "Possibly the human being as well as experimental animals may respond to a physical or emotional stress by an increased activity of the suprarenal cortex. In the same way if for any reason the suprarenal cortex fails in its response and hence if the inhibitory effect of the corticosteroids on the production of thyrotropine does not present, a thyroid hyperactivity is produced." We add that thyroid hyperactivity would aggravate the evolution of leprosy, and so we have-found in our experience.

In this connection we should remember that Dr. OBERDÖRFER proposed the use of diphtheria toxoid as a protection for the suprarenal gland, basing this on his theory of suprarenal insufficiency in leprosy patients due to dietary consumption of sapotoxins.

Taking into account what has been said we should perhaps interpret the $\mathrm{N}$ Factor of ROTBERG as a constitutional variation in the iodine content of the tissues. Hence we can say that human beings lacking the factor of resistance would form a group with too much iodine in the blood, or the Mitsuda-negative patients. On the other hand the human group which possesses the factor of resistance would be Mitsuda-positive and possess too little iodine in the blood. A third group can be separated out, namely the 'indeterminate', which fluctuate from one to the other. This group would coincide or be the analogy of the 'overlapping group' as described by ASTWOOD and CASSIDY, that is patients who cannot be exactly described as hyperthyroid or hypothyroid.

In our experience the lepromatous leprosy patient is able to take many times more than the maximum therapeutic dose usable in the hyperthyroid patients. Therefore it is advised to begin the treatment with dosage not less than $40 \mathrm{mgm}$. daily of methimazole or $120 \mathrm{mgm}$. daily of propyl-thiouracil, until in a few days the progressive dosage is reached which fits the reactions and the development of each patient.

The fear of hypothyroidism is or should be very remote and up to now has not intruded itself except in a very small number of patients. To meet this threat it suffices to suspend the treatment for a necessary time.

In my opinion it is advisable, after 6 to 8 months of treatment by methimazole or by propyl-thiouracil, to use a modern antileprosy drug such as DDS in dosage of 25 to $50 \mathrm{mgm}$. daily.

We should pay attention to the fact that DDS has an undoubtedly antithyroid chemical structure.

The initial violet or erythematous colour of the lepromatous lesions is changed by the treatment into a brownish colour and later takes on a pigmented melanotic tint, remaining thus for an indefinite period of time. The pigmented melanotic tint increases on continuing 
the treatment by antithyroid drugs of the methimazole type. In some persons the melanotic tint decreases if the antithyroid drug dosage is reduced. In other persons there is a new change to a pigmented erythematous tint when the drug is suspended or changed.

Not all leprosy patients are suitable for the antithyroid treatment, but those who benefit most from the use of these drugs are those in whom greatest malignity exists, namely those with diffuse infiltrations, lymphangitis, frequent lepra reactions, papulo-mucosal lesions, also reactional tuberculoid cases, and those with localized signs of obstructive rhinitis, or polyneuritis, or lepromatous patients with hyperaesthesia.

The antithyroid drugs are of very little use in patients who have been treated extensively with other leprostatic drugs and in those very extensively nodular. It is possible that in these latter patients there should first be application of physiotherapy.

As a 'note in the margin' we should like to point out the antithyroid chemical constitution of Ciba- 1906.

The improvement obtained with the antithyroid drugs in leprosy cannot yet be claimed to be permanent, due to the short period of experimentation so far. The questions arising in connection with this new theory are so numerous and the facilities for solving them so few.

From personal communications from Dr. O'BYRNE in recent months it can be said that modifications and progress have been made in the use of antithyroid drugs in the treatment of leprosy. I consider these modifications logical and am in accord with them, as follows:

1. The dosage of methimazole has fluctuated around $100 \mathrm{mgm}$. daily, and of propyl-thiouracil around $500 \mathrm{mgm}$. daily.

2. The therapy of these substances has become associated with what Dr. O'BYRNE calls the 'antithyroid diet', namely a dietary regime in which salt-free iodine is used, an abundance of vegetables of the Brassicae or Crucifera type, a scantiness or suppression of foods too rich in the amino-acid tyrosine, foods which could influence the organic deposition of iodine, the preferential use of poly-desaturated vegetable oils (which have been recognized for a long time as antithyroid).

3. Relative decrease of carbohydrates in the diet and progressive increase in the proteins and in the polysaturated fatty acids.

4. Prohibition of fish and every food of marine origin.

5. The prudent use of wine is advised, or of glucose, in its role as reducing substance.

6. In some cases there has been added to the methimazole or the propyl-thiouracil a solution of sodium thiocyanate in drops up to a 
dose of 300 to $400 \mathrm{mgm}$. daily. This association has the special object to speed up the elimination of iodides by the kidneys in accordance with the observations made by VAN DER LAAN.

7. With the object of decreasing the tissue iodine in lepromatous patients one can equally use the capture of the iodides in the gastrointestinal canal.

We know that the iodine ion eliminated through the gastric juice, the bile, or the other intestinal juices, is absorbed again with great speed and efficiency by the intestine, in such a way that the loss of iodine ion by the intestinal route or foecal route is insignificant. If we administer classic antithyroid drugs to a lepromatous patient, these substances produce the inhibition of the synthesis of the thyroid hormone, that is, interfere with the incorporation of inorganic iodine within the prehormonal organic compounds. Hence we can accept that as a first consequence of the administration of antithyroid substances, there is an increase of the elimination of the iodine ion by the biliary and gastric tract, since the said iodine ion has failed to be used in the making of thyroid hormones.

If simultaneously with the methimazole or with the propylthiouracil we administer a substance which can trap the iodine ion in the intestine, a substance which at the same time would not be absorbable by the intestinal mucosa, we will have succeeded in increasing the elimination of iodine by the foecal route.

The substances which are met with at the present time in experimentation associated with methimazole or propyl-thiouracil are succinyl sulphathiazole and sulphaguanidine.

Some lepromatous leprosy patients treated with these modifications in recent months have obtained appreciable improvement compared with that obtained with the exclusive use of methimazole or propyl-thiouracil.

8. A new path of investigation in order to confirm the possibilities of this theory is quantitative analysis of iodine in the skin of leprotmaous leprosy patients. Such an analysis would be compared with the skin of patients free of leprosy resident in several countries of the world.

\section{Summary}

The logical treatment of leprosy should be related to the iodine metabolism.

The basis of action of antileprosy drugs is the hypoiodaemic concept. To acquire or not acquire leprosy depends on the greater or less proportion of circulating iodine or tissue iodine. The dosage of antithyroid drugs administered to leprosy patients should be greater than that given to hyperthyroid patients. It has been shown that they are well tolerated. 
Not all leprosy patients respond to the action of the antithyroid drugs, just as not all have the same iodine proportion.

The quantitative analysis of skin iodine in patients of lepromatous leprosy cannot be dispensed with.

\section{Acknowledgements}

I have to thank Dr. JAMES Ross InNes for his kindness not only in translating this paper into English, but also for publishing it in Leprosy Review.

I thank Dr. ARturo O'BYRnE for permission to explain some of his ideas on which I have been in constant consultation with him. The collaboration of his indomitable spirit which ever seeks perfection has been much appreciated, also his brotherly friendliness.

\section{Ref erences}

HANSEN, G. H. A. and LoOrT, C. Leprosy: In its clinical and pathological aspects. (Translated by Norman Walker). Bristol, London: John Wright \& Co., 1895. Muir, E. Manual of Leprosy. Edinburgh: E. \& S. Livingstone Ltd., 1948.

Cochrane, R. G. The treatment of leprosy; a review of present-day methods. Leprosy Notes, No. 3 (1928), 6-9.

INNES, J. R. Induced leprotic reaction. Leprosy Rev. (1957), 28, 136-138 (editorial).

Pitt-Rivfrs, R. and Tata Jamshei) R. The Thyroid Hormones. Pergamon Press (1959).

VANDer LaAn, W. P. and Bissel.t., A.: Endocrinology (1946), 39, 157.

PItT-RIVERS, R.: Symposium CIBA sobre Glándula tiroides.

O’Byrne, A. Informe previo a la reunión de Médicos Directores de Dispensarios y Lazaretos de Colombia, Agosto $1^{\circ}$ de 1957; Antitiroideos y Lepra, Mayo de 1958. Primer Congreso Nacional de Leprologia. Cartagéna, Colombia. Int. J. Leprosy, vol. 28, No. 4, 1960.

Avelino Miguez Alonso. Nuestras observaciones sobre la Difenilthiourea en el tratamiento de la lepra. Boletín de servicio Nacional de Lepra, Año VII\# 1 de Marzo 1958. Brasil, Rio de Janeiro.

Jimeno Alfonso y E. Mangas Aznal. Formas atípicas de hipertiroidismo. Revista Clínica Española, Tomo LXXIV 15 de agosto 1959, \# 3.

Nelson de Souza Campos, Luis Marino Bechelli, Abraao Rotberg : Tratado de Leprologia, Volúmen 3, Tomo VI, Epidemiología.

Chaussinand, R. : La Lepra.

Russell, L. CeCIL: Tratado de Medicina Interna. 